\title{
Antiviral activity and mechanism of action of arbidol against Hantaan virus infection
}

\author{
Hai-Rong Xiong, Yi-Hui Zhang, Kan Deng, Qiang Liu, Yuan-Yuan Liu, Fan Luo, \\ Wei Hou and Zhan-Qiu Yang* \\ State Key Laboratory of Virology/ Institute of Medical Virology, School of Medicine, Wuhan University, Wuhan 430071, People's
} Republic of China

*For correspondence: Email: zqyang@whu.edu.cn; Tel: 86-27-68759136; Fax: 86-27-68758766

\begin{abstract}
Purpose: To investigate the activity and mechanism of action of arbidol against Hantaan virus (HTNV) activity by modulating inflammation via TLR-4 pathway.

Methods: HUVEC cells infected with HTNV 76-118 were treated with serially diluted arbidol solutions at $-2 h$ ( $2 h$ before viral infection, pre-treatment mode), $0 h$ (at the same time as viral infection, simultaneous treatment mode) or $2 \mathrm{~h}(2 \mathrm{~h}$ after viral infection, post-treatment mode). The transcript levels of TLR4 were detected by semi-quantitative reverse transcription-PCR (RT-PCR) at 6, 12, 18, and $24 \mathrm{~h}$ later. The levels of iNOS and TNF- $\alpha$ were examined using enzyme-linked immunosorbent assay (ELISA).

Results: Pre-treatment with arbidol, rather than simultaneous treatment or post-treatment, effectively inhibited up-regulation of cellular TLR4 expression (up to $40 \pm 6.1 \%$ inhibition) and activity of supernatant iNOS induced by HTNV infection(up to $44.1 \pm 9.4 \%$ inhibition), as well as in a LPSstimulated inflammatory endothelial cell. Arbidol decreased the elevated TNF-a levels induced by LPS stimulation.

Conclusion: These results are the first evidence that arbidol modulates viral PRRs signaling and its consequential inflammatory cytokine/chemokine response during hantavirus infection.
\end{abstract}

Keywords: Hantavirus, Arbidol, Toll-like receptors, inducible nitric oxide synthase, Antiviral activity, Inflammation

\begin{abstract}
Tropical Journal of Pharmaceutical Research is indexed by Science Citation Index (SciSearch), Scopus, International Pharmaceutical Abstract, Chemical Abstracts, Embase, Index Copernicus, EBSCO, African Index Medicus, JournalSeek, Journal Citation Reports/Science Edition, Directory of Open Access Journals (DOAJ), African Journal Online, Bioline International, Open-J-Gate and Pharmacy Abstracts
\end{abstract}

\section{INTRODUCTION}

Hantaviruses belong to the family, Bunyaviridae, and are associated with two severe forms of hantavirus infections in the human, namely hemorrhagic fever with renal syndrome (HFRS) and hantavirus pulmonary syndrome (HPS), which pose a great threat to human health [1]. Ninety percent of the HFRS cases worldwide were reported in China and mainly caused by two serotypes of hantaviruses-Hantaan virus (HTNV) and Seoul virus (SEOV) [2].
At present, there are no antivirals, or vaccines approved by the Food and Drug Administration (FDA) for the use of hantavirus infection [3]. It is urgent to develop antivirals with novel pharmacological strategies to overcome hantavirus infection. Arbidol is a broad-spectrum antiviral compound that has been shown to have inhibitory effect on influenza virus [4,5], respiratory syncytial virus [6], adenovirus, coxsackievirus [7] and hepatitis $C$ virus infection[8], as well as hantavirus [9]. The 
antiviral mechanism of arbidol is not completely understood. Early studies indicated that arbidol inhibited membrane fusion of enveloped viruses [10-12]. Arbidol also acts as an immunomodulator, which can induce interferon and activate macrophages in viral infectious patients $[13,14]$. Our former study indicates that arbidol efficiently inhibits replication of influenza virus and diminishes acute inflammation through modulating the expression of inflammatory cytokines, which indicate the anti-inflammatory activity of arbidol [5].

In a previous study, the present authors demonstrated that arbidol can inhibit HTNV in vitro and in vivo, and it can modulate the level of serum TNF- $\alpha$ in HTNV-infected mouse [9]. Thus, we initiated this study to investigate how arbidol exhibits its anti-HTNV activity by modulating inflammatory effect via TLR-4pathway. Furthermore, we also analyzed this effect in an acute inflammation cell model stimulated by lipopolysaccharide (LPS), a potent inflammatory mediator.

\section{EXPERIMENTAL}

\section{Cells, virus, and reagents}

Arbidol was provided by Shijiazhuang NO.4 Pharmaceutical. Co. Ltd, Hebei, China. HUVEC cells were obtained from CHISCIENTIFIC and were routinely grown in $\mathrm{F}-12 \mathrm{~K}$ supplemented with $10 \%$ fetal bovine serum (FBS, GIBCO), 0.1 $\% \quad$ L-glutamine, $100 \mathrm{U} / \mathrm{mL}$ penicillin and streptomycin. The F-12K containing $2 \%$ FBS was used for maintaining medium after viral infection. The stocks of Hantaan virus, strain 76118 were obtained from the Institute of Virology, Chinese Academy of Preventive Medicine (Beijing, China) and were propagated on Vero E6 cells. HTNV titration was performed regularly as described previously [9]. Arbidol was provided by Shijiazhuang NO.4 Pharmaceutical. Co. Ltd, Hebei, China. The compound was initially dissolved in $0.05 \%$ dimethyl sulfoxide (DMSO) and then further diluted with maintaining medium.

\section{Experimental design}

The cytotoxicity of arbidol on HUVEC cells was determined by quantitative colorimetric MTT assay as described previously [7]. To investigate the dynamic expression pattern of TLR4 after HTNV infection or LPS stimulation, the HUVEC cells were treated with virus or LPS and subsequently incubated for $6,12,18$, and $24 \mathrm{~h}$.
For arbidol treatment, HUVEC cells were infected with HTNV 76-118 at 100xTCID50 or LPS (100 $\mathrm{ng} / \mathrm{mL}$, S1732, Beyotime Institute of Biotechnology, Shanghai, China), and further treated with serially diluted ARB solutions at $-2 \mathrm{~h}$ ( $2 \mathrm{~h}$ before viral infection, pre-treatment mode), 0 $\mathrm{h}$ (at the same time as viral infection, simultaneous treatment mode) or $2 \mathrm{~h}$ ( $2 \mathrm{~h}$ after viral infection, post-treatment mode), respectively. After $24 \mathrm{~h}$ incubation, the cells were collected for RNA detection by RT-PCR. Four serial dilutions of arbidol $(2.5,5,10,20 \mu \mathrm{g} / \mathrm{mL})$ were tested in triplicate. Viral control, normal control and solvent control were included in all assays. Cells in extra wells from each group were continuously cultured in corresponding medium for 7 days. Immunofluorescence assay (IFA) was used to detect viral antigen and confirm the successful viral infection in each experiment. In the pre-treatment mode, the supernatant from each wells were collected for iNOS or TNF- $\alpha$ detection.

\section{RT-PCR analysis}

Viral RNAs were extracted using TIANamp Virus RNA Kit (Tiangen Biotech Co. Ltd., Beijing) following the manufacturer's instructions. Firststrand cDNA was synthesized by reverse transcription of the total RNA using random primer (Sangon, Shanghai, China) and Moloney murine leukemia virus (M-MLV) Reverse transcriptase(Promega, Beijing, China). Complementary DNA was prepared at $25{ }^{\circ} \mathrm{C}$ for $10 \mathrm{~min}, 42{ }^{\circ} \mathrm{C}$ for $60 \mathrm{~min}, 95{ }^{\circ} \mathrm{C}$ for $5 \mathrm{~min}$ (Eppendorf, USA).The amplification was performed using the following primer sets: TLR4: 5'-CATTGCTTCTTGCTAAATGCTG-3' and 5'GGATTAAAGCTCAGGTCCAGG-3'; GAPDH: 5'GGTGGTCCTCTGACTTCAACA-3' and 5'GTTGCTGTAGCCAAATTCGTTGT-3', respecttively. Thirty-two cycles of PCR were carried out in $25 \mu \mathrm{L}$ reaction mixtures containing $2.5 \mu \mathrm{L}$ synthesized cDNA. A programmed thermal cycler was set as follows: $94{ }^{\circ} \mathrm{C}$ for $180 \mathrm{~s}, 94{ }^{\circ} \mathrm{C}$ for $30 \mathrm{~s}$, and $60{ }^{\circ} \mathrm{C}$ for $30 \mathrm{~s}, 72{ }^{\circ} \mathrm{C}$ for $15 \mathrm{~s}$, and $72{ }^{\circ} \mathrm{C}$ for $5 \mathrm{~min}$. Thereafter, $6 \mu \mathrm{L}$ of each PCR product was loaded onto an agarose gel containing ethidium bromide and separated by electrophoresis. The gel was scanned using the KODAK Gel Logic 212 PRO Imaging System and analyzed using Bandscan 5.0 software, which calculates the ratio of peak value adsorption of TLR4 to that of GAPDH.

\section{Inducible nitric oxide synthase (iNOS) assay}

Inducible nitric oxide synthase (iNOS) activity were determined by a NOS assay kit (Cat no. A014-1, Nanjing Jiancheng Bioengineering 
Institute, Nanjing, China) following the manufacturer's instructions. One hundred microliter sample of each group was half diluted and mixed with $100 \mu \mathrm{L}$ reaction inhibitor solution at room temperature for $3 \mathrm{~min}$. The sample was then incubated with reaction buffer at $37{ }^{\circ} \mathrm{C}$ for $15 \mathrm{~min}$. The reaction was terminated by adding the stop buffer and the absorbance was determined at $530 \mathrm{~nm}$. The activity of iNOS was calculated using equation 1 :

iNOS activity $(\mathrm{U} / \mathrm{ml})=($ ODsample-ODblank $) /(\varepsilon \times \mathrm{b}$ $\times 1500)$

The inhibitory effect of arbidol was evaluated by the following equation 2 :

iNOS inhibitory rate $=($ iNOS unitArbidol-iNOS unitHV)/(iNOS unitNC-iNOS unitHV) $\times 100 \%$.. (2)

\section{TNF- $\alpha$ assay}

TNF- $\alpha$ in the supernatant was detected by Quantikine ELISA kit (R\&D Systems, Minneapolis, MN, USA) according to the manufacturer's instructions. Briefly, $40 \mu \mathrm{L}$ Assay Diluent and $10 \mu \mathrm{L}$ sample were successively added in the microplate and incubated at $37{ }^{\circ} \mathrm{C}$ for $1 \mathrm{~h}$. Plates were washed with PBS, $200 \mu \mathrm{L}$ Conjugate and $200 \mu \mathrm{L}$ substrate solution were added followed by $15 \mathrm{~min}$ incubation at $37{ }^{\circ} \mathrm{C}$. The reaction was terminated with stop solution and the absorbance was determined at $450 \mathrm{~nm}$.

\section{Statistical analysis}

Data are presented as mean \pm standard deviation (SD) and were analyzed by SPSS 17.0 software. One-way ANOVA was used to determine statistical differences for iNOS activity, TNF- $\alpha$ level, and mRNA/ $\beta$-actin ratio. $P<0.05$ was considered to indicate statistical significance.

\section{RESULTS}

\section{Cytotoxicity of arbidol on HUVEC cells}

HUVEC cells were treated with arbidol at different concentrations varying from 2.5 to 40 $\mu \mathrm{g} / \mathrm{mL}$ and cell viability was investigated by MTT assay (Figure 1). Subconfluent monolayers treated with arbidol under $10 \mu \mathrm{g} / \mathrm{mL}$ did not show any visible changes in cell morphology or cell density. The $\mathrm{CC}_{50}$ of arbidol was $17.67 \mu \mathrm{g} / \mathrm{mL}$.

\section{Effect of arbidol on TLR4 expression in HTNV-infected HUVEC cells}

We first analyzed the mRNA expression pattern of TLR4 in HUVEC infected with HTNV and stimulated with LPS. Total RNA was isolated at 6 $\mathrm{h}, 12 \mathrm{~h}, 18 \mathrm{~h}$ and $24 \mathrm{~h}$ post-inoculation and cDNA produced by reverse transcription were subjected to PCR analysis. As shown in Figure 2, TLR4 was expressed at detectable level in both HTNVand LPS- stimulated cells and the expression level after HTNV- and LPS-stimulation are significantly different from the initial normal expression ( $p<0.05$, except of $6 \mathrm{~h}$ in LPS group). The expression pattern in these two groups were similar $(p=0.2815)$.

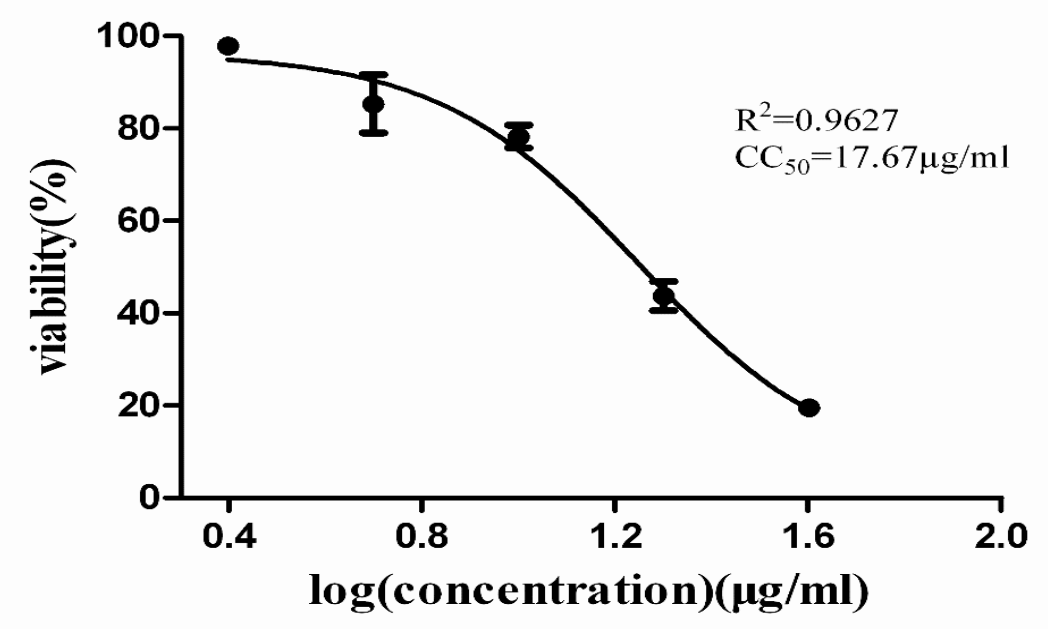

Figure 1: Cytotoxicity of arbidol on HUVEC cells. The cytotoxicity of arbidol on HUVEC cells was determined by quantitative colorimetric MTT assay. The graph was plotted based on logarithm of drug dosage and the $\mathrm{CC}_{50}$ was calculated by Probit regression method 


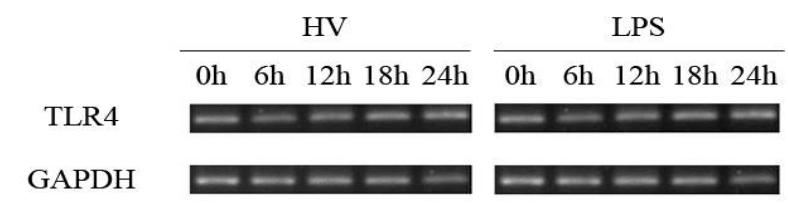

B

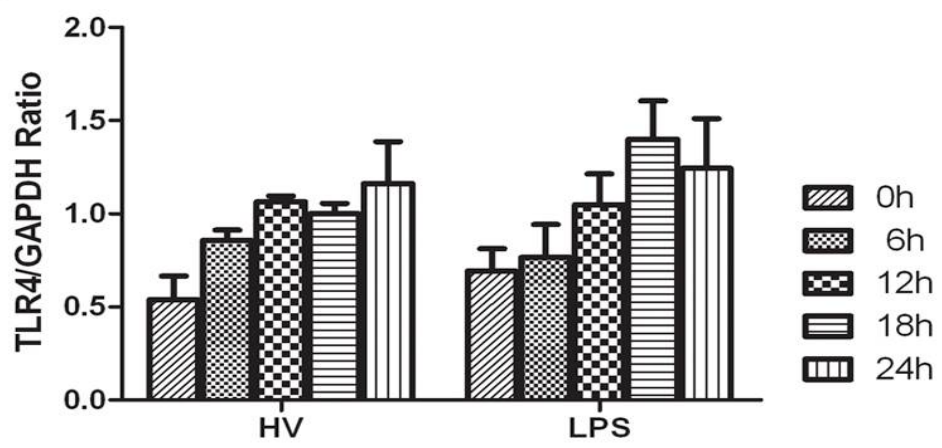

Figure 2: Dynamic expression of TLR4 in Hantavirus- and LPS- stimulated HUVEC cells. At 6, 12, 18 and $24 \mathrm{~h}$ after stimulation, TLR4 expression was determined by semiquatitative RT-PCR as described in Materials and methods. (A). representative agarose gel of DNA generated from primers for TLR4 and GAPDH using RT-PCR. (B). graphic quantification of the TLR4 mRNA after correction by GAPDH. Relative expression of TLR4 against GAPDH. Error bars represent the standard error of mean. The data represents the mean from three independent experiments

We further investigated the effect of arbidol on TLR4 expression in HTNV-infected and LPSstimulated HUVEC cells. Arbidol treatment was applied to different modes as described in Material and Methods. In the pre-treatment mode, arbidol significantly inhibited the upregulated TLR4 expression induced by hantavirus infection or LPS stimulation (Figure $3 A \& B)$. This effect increased with increase in drug concentration. The $20 \mu \mathrm{g} / \mathrm{mL}$ arbidol inhibited around $40 \pm 6.1 \%$ TLR4 expression in HTNV-infected cells, and $50 \pm 1.8 \%$ in the LPS group $(p<0.05)$. In the simultaneous treatment mode, the inhibitory effect was observed only at $20 \mu \mathrm{g} / \mathrm{mL}$ in hantavirus infection group $(p=$ 0.041 , Figure $3 C$ ) or $10.0 \mu \mathrm{g} / \mathrm{mL}$ and $20 \mu \mathrm{g} / \mathrm{mL}$ in LPS stimulation group $(p=0.025, p=0.028$, Figure $3 \mathrm{D}$ ), and not than in the low-concentration groups. In the post-treatment mode, TLR4 expression in HUVEC cells treated with arbidol at $20 \mu \mathrm{g} / \mathrm{mL}$ showed a significant reduction $(p<$ 0.01 , Figure $3 E \& F$ ).

Taken together, pre-treatment with arbidol inhibited the increased TLR4 expression due to hantavirus infection or LPS stimulation in a concentration-dependent manner. High dosage of arbidol also showed inhibitory effects in the other treatment modes.

\section{Effect of arbidol on iNOS in HTNV-infected HUVEC cells}

To test whether arbidol has an impact on $\mathrm{NO}$ production, HUVEC cells were first pre-treated with different concentrations of arbidol for $2 \mathrm{~h}$, and then infected with HTNV or stimulated with LPS. Twenty four hours later, the amount of nitrite in the supernatant was measured. As shown in Figure 4A \& B, elevated levels of nitrite were detected in the supernatant from HUVEC cells after HTNV or LPS stimulation, with approximately 2.8- or 5-fold increase compared to non-infected cells $(p<0.01)$. Arbidol treatments at concentration of 5 and $10 \mu \mathrm{g} / \mathrm{mL}$ inhibited the elevated iNOS with approximately $30.9 \pm 8.1$ and $44.1 \pm 9.4 \%$ respectively $(p<$ $0.05)$. There were no inhibitory effect observed in the high concentration group $(20 \mu \mathrm{g} / \mathrm{mL})$ or low concentration group $(2.5 \mu \mathrm{g} / \mathrm{mL})$.

\section{Effect of arbidol on TNF- $\alpha$ in HTNV-infected HUVEC cells}

It is known that TNF- $\alpha$ induces nitric oxide (NO) through the induction of NOS, thus we tested whether TNF- $\alpha$ was involved in the anti-viral or anti-inflammatory effect of arbidol in HTNVinfected or LPS-stimulated HUVEC cells. The results showed that LPS stimulation, rather than 
HTNV infection, could induce TNF- $\alpha$ production 3.7 times higher than normal control group $(p<$ 0.01 , Figure $4 C \& D$ ). Furthermore, arbidol could

\section{A}

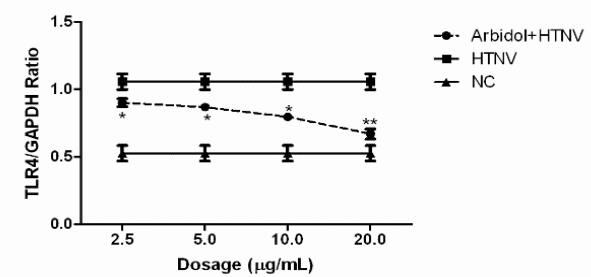

C

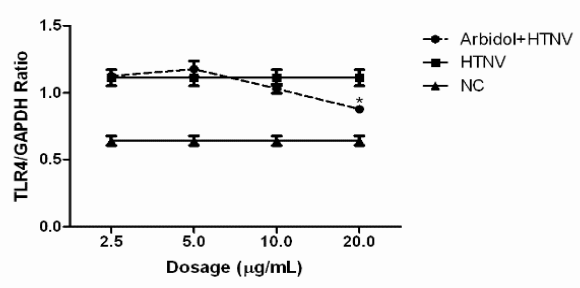

E

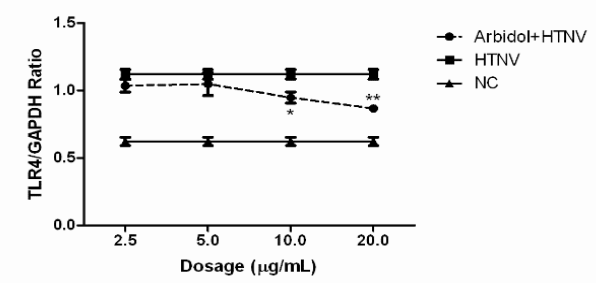

decrease the elevated TNF- $\alpha$ levels induced by LPS stimulation in a concentration-dependent manner (Figure 4D).

B

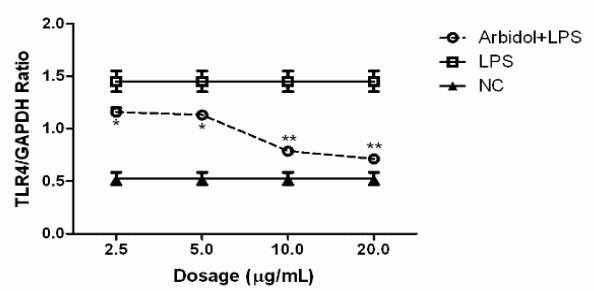

D

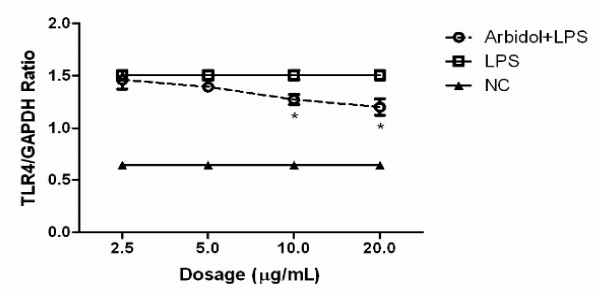

$\mathbf{F}$

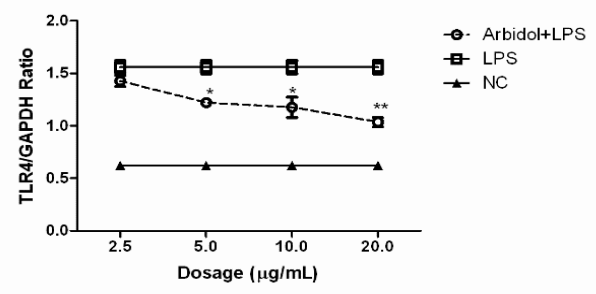

Figure 3: Inhibitory Effect of arbidol on TLR4 expression in Hantavirus- and LPS- stimulated HUVEC cells via different modes. HUVEC cells infected with $\operatorname{HTNV}(A, C, E)$ or LPS (B, D, F) were treated with serially diluted arbidol solutions at $-2 \mathrm{~h}$ (pre-treatment, $\mathrm{A \& B}$ ), $0 \mathrm{~h}$ (simultaneous treatment mode, $\mathrm{C} \& \mathrm{D}$ ) or2 $\mathrm{h}$ (post-treatment mode, $E \& F$ ), respectively. $Y$ axis represents relative expression of TLR4 against GAPDH in different groups. ${ }^{*} p<0.05$ vs. control group, ${ }^{* *} p<0.01$ vs. control group

A

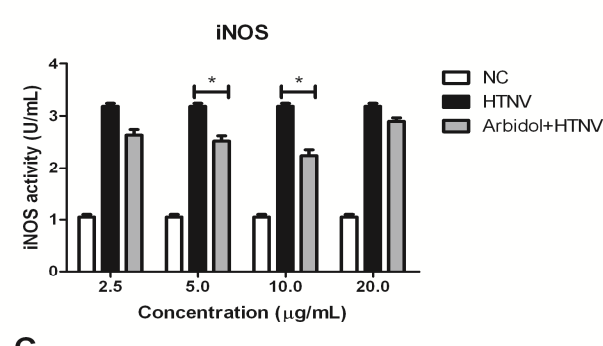

C
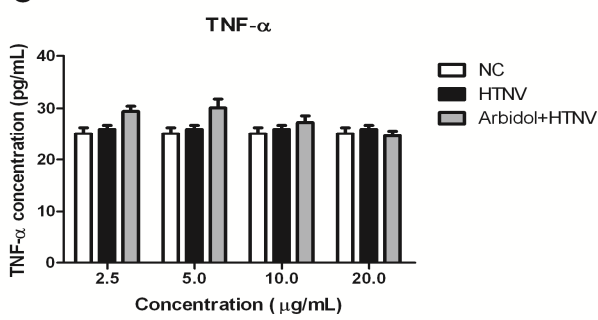

B

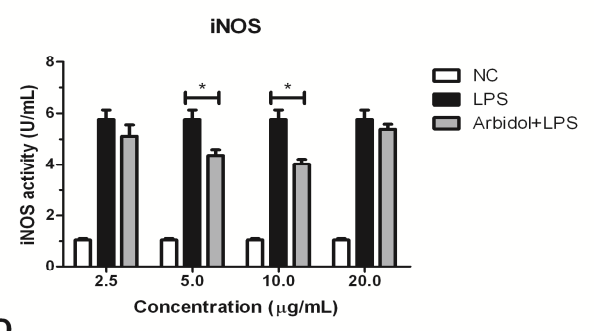

TNF- $\alpha$

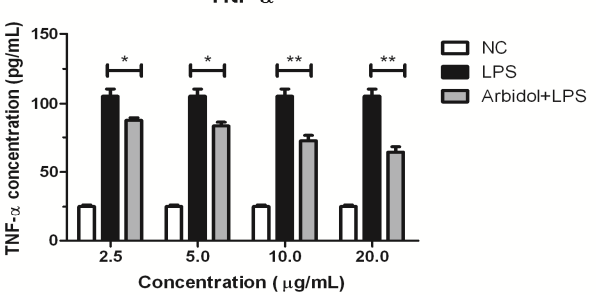

Figure 4: Effect of arbidol on iNOS activity and TNF- $\alpha$ production in HTNV- and LPS- stimulated HUVEC cells. HUVEC cells were treated with serially diluted arbidol solutions for $2 \mathrm{~h}$ and subsequently infected with HTNV (A, C) or LPS (B, D), respectively. The iNOS activity (A, B) and TNF- $\alpha$ production $(C, D)$ in the supernatant were measured; ${ }^{*} p<0.05$ vs. stimulation group; ${ }^{* *} p<0.01$ vs. stimulation group 


\section{DISCUSSION}

Arbidol is a small antiviral compound with a broad-spectrum inhibitory effect. We have previously shown that arbidol could inhibit HTNV in vitro and in vivo. Here, our results demonstrated that arbidol could inhibit the upregulation of cellular TLR4 expression as well as iNOS induced by HTNV infection, and also inflammation stimulated with LPS.

It has been reported that HTNV induces TLR4 expression in virus-infected EVC-304 cells, leading to enhanced production of IFN- $\beta$, IL-6 and TNF- $\alpha$ [15]. Arbidol possesses comprehensive pharmacological properties and is also known as an immunomodulant and interferon inducer. However, Boriskin et al found that arbidol inhibited acute HCV infection without affecting RIG-I and IFN signaling pathway [8], which implied other antiviral mechanisms of arbidol besides interferon induction. We found that arbidol inhibited the increased TLR4 expression due to hantavirus infection or LPS stimulation, especially in the pre-treatment group in a concentration-dependent manner. This result suggests that arbidol may regulate the TLR4mediated innate immune response in the HTNVinfected HUVECs.

We further tested if arbidol could modulate the inflammatory cytokines/chemokines produced by antiviral innate response during HTNV infection. Increased amounts of iNOS have been detected in patients with hantavirus-related disease, which could facilitate immunopathological processes during the infection $[16,17]$. Administration of a specific iNOS inhibitor significantly improved survival in hantavirus-infected murine model with HCPS-like disease [16]. We found that median concentration of arbidol could attenuate the elevated iNOS level in HTNV- or LPS- stimulated HUVECs, which suggests that arbidol may alleviate the pathological consequences of HTNV infection/acute inflammation via inhibition of iNOS generation.

It has been reported that hantavirus infection can up-regulate the production of TNF- $\alpha$ in HFRS patients $[18,19]$. Niikura et al demonstrated that TNF- $\alpha$ could extend the duration of increased vascular permeability of the HTNV-infected HUVEC [20]. It could also induce nitric oxide (NO) through induction of NOS [21]. We tried to examine if arbidol could inhibit the production of iNOS via suppression of TNF- $\alpha$ expression. However, our results showed that arbidol could decrease the elevated TNF- $\alpha$ levels induced by LPS stimulation in a concentration-dependent manner. We did not detect any change of TNF- $\alpha$ in the supernatant of HTNV-infected HUVECs, nonetheless, other in vitro studies reported that infection of immature dendritic cells or human alveolar macrophages with hantavirus weakly upregulated TNF- $\alpha$ production.

We assume that the HTNV infection of HUVEC itself did not induce TNF- $\alpha$ production as it did in other cell lines or the production level is too low and beyond the detection range in our system. Previously we have found that arbidol could modulate TNF- $\alpha$ response in HTNV-infected suckling mice [9], we presumed that arbidol may modulate the inflammatory chemokine in an integral animal infection model rather than cell infection model.

\section{CONCLUSION}

Arbidol inhibits TLR4 expression and iNOS production induced by HTNV infection in HUVECs, which represents one of the virussensing pattern-recognition receptors (PRRs) and its consequential inflammatory cytokines/chemokines. Further experiments are needed to investigate the in-depth mechanism of action of aribidol.

\section{DECLARATIONS}

\section{Acknowledgement}

This work was supported by National Mega Project on Major Drug Development (no. 2009ZX09301-014-1), National Natural Science Foundation of China (NSFC Project nos. 30873104 and 81000734) and Fundamental Research Funds for Central Universities (no. 4101045).

\section{Conflict of Interest}

No conflict of interest associated with this work.

\section{Contribution of Authors}

The authors declare that this work was done by the authors named in this article and all liabilities pertaining to claims relating to the content of this article will be borne by them.

\section{REFERENCES}

1. Jonsson CB, Figueiredo LT, Vapalahti O. A global perspective on hantavirus ecology, epidemiology, and disease. Clin Microbiol Rev 2010; 23: 412-441.

2. Chen $H X$, Luo CW, Chen F, Wang XH, Yang JH, Ma LJ, Hu JY, Sun HY, Yao ZH, Qiu JC. Study and surveillance 
of HFRS( Hemorrhage Fever with Renal Syndrome) in China. Chinese Journal of Public Health 1999; 15: 616623.

3. Safronetz $D$, Haddock $E$, Feldmann $F$, Ebihara $H$, Feldmann $H$. In vitro and in vivo activity of ribavirin against Andes virus infection. PLoS One 2011; 6: e23560.

4. Leneva IA, Fediakina IT, Gus'kova TA, Glushkov RG. [Sensitivity of various influenza virus strains to arbidol. Influence of arbidol combination with different antiviral drugs on reproduction of influenza virus A]. Ter Arkh 2005; 77: 84-88.

5. Liu Q, Xiong HR, Lu L, Liu YY, Luo F, Hou W, Yang ZQ. Antiviral and anti-inflammatory activity of arbidol hydrochloride in influenza A (H1N1) virus infection. Acta Pharmacol Sin 2013; 34: 1075-1083.

6. Shi L, Xiong $\mathrm{H}, \mathrm{He} J$, Deng $H, L i \mathrm{Q}$, Zhong $\mathrm{Q}$, Hou W, Cheng $L$, Xiao $H$, Yang Z. Antiviral activity of arbidol against influenza $A$ virus, respiratory syncytial virus, rhinovirus, coxsackie virus and adenovirus in vitro and in vivo. Arch Virol 2007; 152: 1447-1455.

7. Zhong Q, Yang Z, Liu Y, Deng H, Xiao H, Shi L, He J. Antiviral activity of Arbidol against Coxsackie virus B5 in vitro and in vivo. Arch Virol 2009; 154: 601-607.

8. Boriskin YS, Pecheur El, Polyak SJ. Arbidol: a broadspectrum antiviral that inhibits acute and chronic $\mathrm{HCV}$ infection. Virol J 2006; 3: 56.

9. Deng $H Y$, Luo F, Shi $L Q$, Zhong $Q$, Liu YJ, Yang ZQ. Efficacy of arbidol on lethal hantaan virus infections in suckling mice and in vitro. Acta Pharmacol Sin 2009; 30: 1015-1024.

10. Boriskin YS, Leneva IA, Pecheur El, Polyak SJ. Arbidol: a broad-spectrum antiviral compound that blocks viral fusion. Curr Med Chem 2008; 15: 997-1005.

11. Leneva IA, Russell RJ, Boriskin YS, Hay AJ. Characteristics of arbidol-resistant mutants of influenza virus: implications for the mechanism of anti-influenza action of arbidol. Antiviral Res 2009; 81: 132-140.

12. Teissier E, Zandomeneghi G, Loquet A, Lavillette $D$, Lavergne JP, Montserret R, Cosset FL, Bockmann A, Meier BH, Penin F, et al. Mechanism of inhibition of enveloped virus membrane fusion by the antiviral drug arbidol. PLoS One 2011; 6: e15874.
13. Glushkov RG, Gus'kova TA, Krylova L, Nikolaeva IS. Mechanisms of arbidole's immunomodulating action. Vestn Ross Akad Med Nauk [in Russian] 1999: 36-40.

14. Silin DS, Lyubomska OV, Ershov FI, Frolov VM, Kutsyna $G A$. Synthetic and natural immunomodulators acting as interferon inducers. Curr Pharm Des 2009; 15: 12381247.

15. Jiang $H$, Wang $P Z$, Zhang $Y, X u Z$, Sun $L$, Wang $L M$, Huang CX, Lian JQ, Jia ZS, Li ZD, et al. Hantaan virus induces toll-like receptor 4 expression, leading to enhanced production of beta interferon, interleukin-6 and tumor necrosis factor-alpha. Virology 2008; 380: 5259.

16. Davis IC, Zajac AJ, Nolte KB, Botten J, Hjelle B, Matalon $S$. Elevated generation of reactive oxygen/nitrogen species in hantavirus cardiopulmonary syndrome. $J$ Virol 2002; 76: 8347-8359.

17. Linderholm M, Groeneveld PH, Tarnvik A. Increased production of nitric oxide in patients with hemorrhagic fever with renal syndrome--relation to arterial hypotension and tumor necrosis factor. Infection 1996; 24: 337-340.

18. Linderholm M, Ahlm C, Settergren B, Waage A, Tarnvik A. Elevated plasma levels of tumor necrosis factor (TNF)-alpha, soluble TNF receptors, interleukin (IL)-6, and IL-10 in patients with hemorrhagic fever with renal syndrome. J Infect Dis 1996; 173: 38-43.

19. Liu JM, Zhu Y, Xu ZW, Ouyang WM, Wang JP, Liu XS, Cao YX, Li Q, Fang $L$, Zhuang $R$, et al. Dynamic changes of apoptosis-inducing ligands and Th1/Th2 like subpopulations in Hantaan virus-induced hemorrhagic fever with renal syndrome. Clin Immunol 2006; 119: 245-251.

20. Niikura M, Maeda A, Ikegami T, Saijo M, Kurane I, Morikawa S. Modification of endothelial cell functions by Hantaan virus infection: prolonged hyper-permeability induced by TNF-alpha of hantaan virus-infected endothelial cell monolayers. Arch Virol 2004; 149: 12791292.

21. Bove K, Neumann P, Gertzberg N, Johnson A. Role of ecNOS-derived NO in mediating TNF-induced endothelial barrier dysfunction. Am J Physiol Lung Cell Mol Physiol 2001; 280: L914-922. 